\title{
Problems and Countermeasures of Network Food Safety in China
}

\author{
Pingfang Yang \\ International Business School \\ Yunnan University of Finance and Economics, \\ Kunming, China \\ 93039219@qq.com
}

\begin{abstract}
In recent years, more and more foods are sold via the Internet. At the same time, network food safety is much concerned by the consumers. First, we analyze network food safety problems and difficulties in supervision and safeguarding legal rights. Secondly, we propose some countermeasures to solve these problems and difficulties, i.e., perfecting laws, regulations and standards related to network food safety, fulfilling the responsibilities for network food safety, improving the abilities to supervise network food safety, and strengthening self-regulation of network food enterprises and the industry. The suggestions are useful for the government and food enterprises to establish a safe environment of network foods.
\end{abstract}

Keywords-network food safety; takeaway; credit system; supervision

\section{INTRODUCTION}

Food safety has emerged as an important global issue with international trade and public health implications (WHO, 2006) In recent years, there has been increasing public concern for food safety in China, and media attention to food safety issues has been increasing. On April 7, 2015(the World Health Day), the World Health Organization (WHO) chose to focus on food safety.

Chinese president Xi Jinping used "two issues" to illustrate the importance of the problem of food safety, i.e., it is not only an important livelihood issue, but also an important political issue. In May 2015, he stressed to strengthen food and drug safety supervision, speed up the construction of scientific and perfect system about the governance of food and drug by means of the most serious standards, the strictest supervision, the most severe punishment, and the most serious accountability.

In 13th Five-Year Planning proposals of China, the problem of food safety is raised to the top of national strategy. It is required to implement food safety strategy, and form a system of food safety governance which is strict and efficient, and with the feature of society multi-governance, so as to make people eat at ease.

In recent years, with the improvement of the function and convenience of mobile phone, and the enlargement of coverage of $4 \mathrm{G}$ and WIFI, more and more people use mobile APP to complete various kinds of business activities. Compared with before, people's food, clothing, shelter and means of traveling are connected with mobile network in a certain degree, and become more convenient and quick. According to the survey of CNNIC, in the first half of 2017, the rising speed of users for application of mobile phone out selling ranks top one, i.e., increasing rate in the first half of 2017 is $40 \%$, which is much higher than that of Internet shopping(10.2\%) and online tourism $(11.5 \%)$

With several rounds of investment of Internet tycoons such as Alibaba and Tencent, and the subsidy battle in takeaway market during 2015-2016, many takeaway platforms have withdrawn from the competition. By the end of 2017, the market share of Meituan Takeaway, Eleme and Baidu Takeaway is $53.9 \%, 29.8 \%$ and $13.7 \%$ respectively, and their total share is $97 \%$. O2O catering is very popular in consumers because it can bring high efficient and convenient dining experience to consumers, and it has great potential in development [7].

The virtualization and anonymity of online trading products takeaway makes the existence of information asymmetry between the seller and the buyer, and incident frequent exposure of the black factory makes the whole takeaway industry get into a crisis of confidence. There are many kinds of problems in the takeaway market, such as not sending meals at the right time, leaving out or incorrectly sending of foods, and unqualified foods.

In section two, we review the literatures on food safety and network food safety. In section three, the problems of network food safety are discussed. In the last section, some countermeasures are put forward.

\section{LITERATURE REVIEW}

Many researchers have studied food safety issues and the approaches of ensuring food safety.

L. Manning, R.N. Baines identify the issues for an organization if their management system is focused primarily on minimizing quality costs rather than producing safe, wholesome food [1]. David L. Ortega et al. explore Chinese food safety issues by analyzing select incidents within the Chinese agricultural marketing system. A marketing utility framework is utilized to discuss some of the major food safety

*Corresponding author 
incidents in China and potential solutions are explored [2]. Annabelle M. Wilson et al. report how food regulators communicate with consumers about food safety and how they believe consumers understand their role in relation to food safety. They found that food regulators have a key role in communicating information to consumers about food safety and food incidents [3]. Liu Peng and Zhang Sujian argued that China's food safety regulatory system has experienced three stages since 1992: multi-level management, semi-vertical management and mixed management dominated by local management. The transformation of the three stages is tightly connected with the regulation and reform of China's central local government relationship undergone since 1990s. The author found out the deficiency of current mixed management system and therefore "regulatory federalism" should be employed, establishing a more scientific and effective regulatory regime and fostering a collaborative regulatory system between the central-local government [4]. Zhang Guoxing et al. establish an evolutionary game model and analyze the mechanism where third party supervision influences the behavior of food enterprises and government supervision departments. It is found that to some extent the third-party intendance can replace the supervisory role of government supervision departments [5]. Zhao Yan suggests leveraging "Internet plus" way of thinking and technical means and making use of information platform, to accelerate the construction of electronic supervision system for food safety, strengthen the food safety traceability management and whole process supervision, and establish an integrated social supervision system combining government regulation and public supervision, so as to realize the full and fine food safety management [6].

Zhang Zhixiang and Shi Kuiran discuss the problems in the development of takeaway and use certain knowledge of game theory to give a thorough research on the safety of take away on $\mathrm{O} 2 \mathrm{O}$ platform. The supervision model is built so that the takeaway safety will go towards good condition by increasing the food regulatory authorities and law enforcement [8]. You Wenyin and Luo Jinyong analyze several problems existing in current network of food, such as food quality problem, seller's credit problems and consumer rights issues, and put forward some corresponding countermeasures to improve the network current food safety problem and effectively protect the interests of consumers [9]. Network food supervision in China is in an initial stage, the laws and regulations are not perfect, and some problems have not fully exposed [10].

Food Safety Law is revised and enacted on October 1, 2015. It is regarded as the most severe law in food safety in the history. In this law, eight aspects of institutional design guarantee the strictest supervision, six aspects of penalty guarantee severe punishment, four aspects of stipulation guarantee that food safety is governed by the whole society, and three obligations strengthen the supervision of online food transaction. In Food Safety Law enacted in 2015, the concept of third party platform of network food is put forward, this means that network food is formally supervised according to the new law. Once the platform finds illegal activities, it should stop them and report to the department monitoring food safety.
However, because of the specialness of selling food online, imperfection of credit system, and supervising of network food is in a starting stage, problems of network food are arising. The virtualization and border-crossing of online food and beverage result in the challenges to administration governing, cases investigation, evidence determination, penalty implementation and consumer's rights protection.

In 2016, Investigating and Punishing Regulation for Illegal Action in Network Food Safety is enacted by the State Food and Drug Administration. Departments monitoring food safety place more force on management and controlling, and the whole society and the media positively participate in the governance of food safety, so a good situation of joint management has been formed. According to this regulation, the producer and businessman of network food should get permission by law, and show it in an obvious place on business web page, while the third party platform of network food has the responsibility to check the license, and put on record in the department monitoring food safety in thirty working days. So those sellers without license will be forced to leave the trading platform.

\section{MAIN PRoblems IN Network FoOd SAFETY AND MANAGEMENT}

Generally speaking, food safety problems are due to governance failure and market failure. Network food brings new challenge to administration jurisdiction, investigation of cases, implementation of punishment, and protection of consumer's rights and interests.

\section{A. Frequent Occurrence of Defrauding}

Network food is not traded by face to face way. In an online store, only pictures of goods are shown. Information about goods is inadequate. Consumers can only judge by means of evaluation information of sellers. Some sellers sell forged and fake commodity and foods of quality inconsistent with price. Some even repaint production date of outdate foods or foods withdrawn from physical store and sell them online. For network foods self-produced or packed in bulk, there is no special manufacturing place, they are produced in home or renting rooms, without standard disinfection and quarantine environment, and was produced packed simply. Some network foods have no formal packing identification. Information such as production date and shelf life has not been written on it obviously. Some imported foods have no formal origin, without Chinese label or qualified inspection and quarantine procedure. In addition, some network foods require better transportation condition, but they have to be transported with other goods in present logistic system, so potential safety hazard is bigger.

By the end of 2017, the market share of Meituan Takeaway, Eleme and Baidu Takeaway is $53.9 \%, 29.8 \%$ and $13.7 \%$ respectively, and their total share is $97 \%$. A survey about the business qualification of sellers on Eleme and Meituan shows that only $11.3 \%$ and $10.6 \%$ of their sellers are qualified. The media has exposed the black workshops on Meituan and Eleme. Their sanitary condition is dreadful to our mind. 
On some platforms selling network foods, there exists the phenomenon of clicking farm and good evaluation, with the aim of misleading consumers and getting more benefits.

In recent years, some overseas foods get into China with the population of Internet. However, their realness and safety problems have not been monitored.

\section{B. More Difficulties in Safeguarding Legal Rights and Complaining}

In general, network foods are traded through the third party platforms, and most online stores have no physical stores. In these online stores, the boss is both the purchaser and customer's server. Some online stores have no business qualification and invoice, so once a food safety issue occurs, the consumer is not easy to get the evidence for safeguarding his or her legal rights. On the other hand, network foods are often traded at a place other than the consumer's own hometown, and the amount of trading is very small, some of them even come from abroad. If the consumer can't reach an agreement with the seller after a food safety issue occurs, he or she needs to hand in an application to the third party platform for safeguarding legal right and last a long time. Many consumers are afraid of trouble and do not prefer to spend energy to safeguarding their legal rights, so they often give up safeguarding rights, which will promote illegal behaviors of unscrupulous operators.

\section{Hard to Enforce Supervision and Inspection}

On one hand, laws and regulations related to network food are relatively lagging, and they can't meet the needs of the development of new commercial form and new technology in the field of network food. On the other hand, network foods are traded through the third party platforms, while market access threshold is low and most online stores have no physical stores. This makes it more difficult for enforcement departments to supervise network food safety. At present, enforcement inspection of network food safety and non-network food safety is responsible by food inspection departments at each level. Network food transaction often breaks through geographic restriction. Due to many reasons such as less work outlay, weak supervision forces, complex management levels, and not so smooth for information change, enforcing supervision and inspection work faces huge challenges.

\section{SUGGESTIONS ON SUPERVISION OF NETWORK FOODS SAFETY}

\section{A. Perfect Laws, Regulations and Standards Related to Network Food Safety}

China has basically formed the legal framework for food safety. For example, Food Safety Law, as the Basic Law, was supplemented by related regulations, local laws and regulations, and judicial interpretations, and is compatible with other laws. However, there are problems related to low legal effect and light punishment in our food safety laws and regulations.

Food Safety Law and Investigating and Punishing Regulation for Illegal Action in Network Food Safety, enacted in 2015 and 2016 respectively, have stipulated legal obligations and responsibilities of producers and businessmen of network foods, providing legitimate basis for network food safety supervision [11]. However, due to specificity and complicity of network food production and business, these two laws can't stipulate detailed legislation clauses on network food safety management. Therefore, all parts of the country should lay down rules for the implementation and administrative measures according to the situation of local supervision, so as to establish a legal system covering the whole industrial chain of network foods, including food producing, processing and circulating. Market threshold for network food production and business should be raised, and privately or individually-owned business should be forbidden to enter the field of network food.

The standard of network food safety is very important. The government should reference international standard and consider the situation of network food safety supervision of China, and then lay down and perfect some standard about the production, storage, transportation and sale of network foods.

The most important reason why food safety problems often happen despite repeated prohibition is that the government's punishment on dishonest behaviors of food producers and entrepreneurs is light. Hence, Laws and regulations must strengthen punishment on illegal activities related to network food safety and expose the cases to the public, so as to raise the dishonesty cost and unlawful cost.

\section{B. Fulfil the Responsibilities for Network Food Safety}

First, the responsibilities of producers and businessmen of network foods should be implemented. Producers and businessmen of network foods should build the traceability system, and strictly fulfill all the institutions related to network food, for example, record of the process of network food production and business, risk management, product recall, and emergency disposal, and so on.

Second, the responsibilities of supervision of local government should be implemented. We should stress governance at the source of network foods, and strengthen monitoring the enterprises above designated size which produce network foods or provide raw materials and responsible for packing. For small food workshops and refreshment kiosk, grass-roots management unit in the county and villages and towns may take their advantage of being bound up with the masses, and use new media such as weixin and microblog to collect information about network foods. In addition, they should strengthen regular supervision, and carry out periodical inspection and spot check, so as to strengthen source management. The supervision of food safety involves many departments, so these departments should strengthen the supervision of all stage, including production and processing, circulation and consumption, and innovate the methods of supervision. Meanwhile, they should strengthen coordination, especially in the context of overlap in work.

Third, the third party platforms should take an attitude of responsible for the consumers, and strictly check the qualification of sellers doing business on their platforms, inspect the supply channels, processing location and food transport way. Once finding some issues, they should ask the sellers to correct or solve. For those sellers who produce foods 
themselves, the platform should monitor the whole process of food production. The platform should distinguish the seller's contact information, mailing address and business license to assure the sellers' information is true. At the same time, the platform should establish a mechanism of quick compensation. Once receiving a complaint about network foods, it should positively response to the consumer and help him/her to safeguard his/ her legal right.

\section{Improve the Abilities to Supervise Network Food Safety}

On one hand, a monitoring system of network food safety should be established. This system should take national network food monitoring institution as the center and local monitoring institution as the base, and aim at sharing data and coordinating technology and work. By this way, we can monitor all the actions and the whole process of production and business of network food. From the angle of management, a professional team responsible for network inspection should be organized, which works together with the institution monitoring network food information in food and drug administration. On the whole, food safety inspection means in many regions of China (especially in the west) is relatively backward, which is reflected in the food safety inspection equipment and inspection technology. The government should increase financial investment to support equipments replacement and the construction of database, so as to use big data, cloud computing and intelligent terminal to collect information about network foods and evidence of illegal actions.

We should establish and perfect credit management mechanisms such as collecting credit information, sharing credit information and punishing the dishonest behaviors [12]. Network food safety credit management should rely on the guidance of the government and the governance of the whole society. By this way, we can make full use of credit intermediary organization, media, consumers, and put all kinds of information into credit information system, including consumer's complaints, media exposure, enterprises' credit evaluation by credit intermediary organization, tax records, environment protection records, price records, and the inspection results of quality sector, etc.

\section{Strengthen Self-Regulation of Network Food Enterprises and the Industry}

In order to complete network food safety management, besides the supervision of the departments of the government, self-regulation of enterprises and the industry is also necessary. On April 20, 2017, Meituan Takeaway, Eleme, Baidu Takeaway and Home Food Club organized an industry selfdiscipline alliance of online food ordering platform, and signed "Convention on self-discipline and co-construction alliance of online food ordering platform" in Beijing. The convention promised to the public from fourteen aspects, including the inspection of entering the platform, ordinary management, punishment on illegal actions and sunshine food and beverage, etc. The foundation of this alliance is an exploration of using data resource advantage accumulated in the platforms to provide information for the policy-making and risk analysis of network food safety management by the government. This is a good beginning of self-regulation of network food enterprises and the industry.

\section{CONCLUSIONS}

With the rapid development of network and information technology, and the population of mobile phones, network foods become popular in urban areas. However, many problems related to network food safety consequently appear. To solve these problems, the government should perfect the laws and strengthen supervisions, while network food enterprises and the industry should regulate themselves.

\section{ACKNOWLEDGMENTS}

This research was supported by the National Natural Science Foundation of China under Grant 71362016, the Scientific Research Foundation of Yunnan Provincial Department of Education under Grant 2012Y125, and the Scientific Research Foundation of Yunnan University of Finance and Economics under Grant YC2012A21.

\section{REFERENCES}

[1] L. Manning, R.N. Baines. Effective management of food safety and quality. British Food Journal, Vol. 106, Iss 8, 2004, pp. 598-606.

[2] David L. Ortega, Colin G. Brown, Scott A. Waldron, H. Holly Wang Agricultural marketing and food safety in China: a utility perspective. Journal of Agribusiness in Developing and Emerging Economies, Vol.4, Iss1. 2014, pp. 23-31.

[3] Annabelle M. Wilson, Samantha B. Meyer et al. How food regulators communicate with consumers about food safety, British Food Journal Vol. 117, Iss 8, 2015, pp. 2129-2142.

[4] Liu Peng, Zhang Sujian. Toward Regulatory Federalism: A Study on the Vertical Power Distribution of China's Food Safety Regulatory System. Journal of Huazhong Normal University(Humanities and Social Sciences) ,Vol.54, 2015, 1:28-34. (In Chinese)

[5] Zhang Guoxing, Gao Wanxia, Guan Xin. Evolutionary game model of food safety supervision based on the third-party intendance. Journal of systems Engineering, Vol.30, 2015, 2: 153-164. (In Chinese).

[6] Zhao Yan. Relying on the "Internet plus" to construct a new mode of food safety supervision. Economic Research Guide, 2016, No.2:114-116. (In Chinese).

[7] Zhang Wei. Development Report of Takeaway O2O Industry in China shows expansion service in takeaway platform represents the trend. Chinese Food, 2016, No.703(15): 48-59. (In Chinese).

[8] Zhang Zhixiang, Shi Kuiran. Research on the Safety of Takeaway on O2O PLatform. Food Industry. Vol. 38, 2017, No.1: 218-220. (In Chinese).

[9] You Wenyin, Luo Jinyong. The Problems and Countermeasures of the Current Network Food Safety. Modern Food, 2017, No.3: 45-47. (In Chinese).

[10] Tian Yibo. Problems and countermeasures of current network food safety. China Food Safety, 2017, No.3: 31-32. (In Chinese).

[11] Yan Tao. Reinforcing the supervision of network food safety should start from legislation. Capital Food Medicine, 2017, No.2: pp. 26. (In Chinese).

[12] Song Guangxing, Tian Tian. Study on China's Food Safety Issues and Supervision Platform Based on Credit Management. Proceedings of 2012 International Conference on Public Management. 2012, pp.323334.

[13] Yang Yu, Wu Zhimi. A comparison of domestic and international food safety supervision mechanism. China Health Law, Vo1. 24, 2016, 2:3033. (In Chinese). 